\title{
Epigenetics and Hematopoietic Stem or Progenitor Cells
}

\author{
Yang Wang, Benjamin T. Moore, Xianhao Peng and Peng Xiao*
}

Osteoporosis Research Center, Creighton University Medical Center Omaha, NE 68131, USA

\begin{abstract}
The maintenance and differentiation of hematopoietic stem/progenitor cells (HSPCs) is a critical process of hematopoiesis that includes the formation of lymphoid lineage and myeloid lineage. Epigenetic regulation is mainly composed of DNA methylation, histone modifications, non-coding microRNA (miRNA) regulation and chromatin remodeling, which are essential for the maintenance and differentiation of hematopoietic stem/progenitor cells (HSPCs). This review details the epigenetic studies of four major epigenetic mechanisms in normal and aberrant HSPCs, as well as hematopoiesis.
\end{abstract}

Epigenetics is the study of heritable changes in gene function caused by mechanisms other than changes in the underlying DNA sequence and is mainly composed of DNA methylation, histone modifications, non-coding microRNA (miRNA) regulation and chromatin remodeling [1-3]. Epigenetic regulation is essential for the maintenance and differentiation of hematopoietic stem/progenitor cells (HSPCs), a critical process of hematopoiesis that includes the formation of lymphoid lineage cells, such as $\mathrm{T}$ and $\mathrm{B}$ cells and the constitution of myeloid linage cells, such as neutrophils, eosinophils, basophils, monocytes, macrophages, megakaryocytes, platetes and erythrocytes $[4,5]$. The understanding of the epigenetic biomarkers and the mechanisms of epigenetic regulation in the normal and abnormal development of HSPCs will benefit the diagnosis and therapy of blood and immune diseases, such as myelodysplastic syndromes (MDS) and various subtypes of leukemia.

\section{DNA Methylation and HSPCs}

DNA methylation occurs at position C5 of cytosine in $\mathrm{CpG}$ dinucleotides. The DNA methyltransferases (DNMTs), such as DNMT1, DNMT3A and DNMT3B, are required for the maintenance of DNA methylation patterns [6]. The gene expression regulated by DNA methylation of the gene promoter regions is critical for developmental processes [7-9].

\section{DNA methylation and normal HSPC development and differentiation}

DNA methylation is a key mechanism for normal HSPC development and hematopoiesis. The DNA methyltransferases are important for HSPC development. DNMT1 plays a significant role in the self-renewal of adult hematopoietic stem cells (HSCs) and DNMT1-deficient HSCs intended to differentiate into multilineage hematopoietic cells, particularly into myeloid progenitor cells [10]. Reduced DNMT1 activity resulted in the differentiation of mouse HSCs into myeloerythoid, but not lymphoid, progeny [11]. In addition, DNMT3A and DNMT3B are critical for HSC relf-renewal but not differentiation [12]. DNMTs mediate the genomic DNA methylation levels in HSPCs. There are several genome-wide DNA methylation studies that have identified differential stages of HSPCs [13-17]. Bisulfite sequencing analysis identified that $\mathrm{CpG}$ dinucleotides colocalize across defined regulatory regions of lineage-affiliated genes in HSCs [17]. CD34 is a specific membrane protein marker for HSPCs [18-21]. A comparison of genome-wide CpG methylation levels in human CD34+ and CD34- cells found a characteristic undermethylation dip around the transcription start site of promoters and an overmethylation of flanking regions in undifferentiated CD34+ cells [16]. A study examined 4.6 million CpG sites and obtained comprehensive differential methylome maps of different hematopoietic progenitors [15]. Bocker et al. [14] indentified differential genome-wide promoter DNA methylation levels of human HSPCs during differentiation and aging. Particularly, by comparing CD34+ HSPCs to myeloid cells, they identified a defined set of differentiated-related genes that are hypermethylated in HSPCs. They also compared HSPCs between fetuses and adults and observed a bimodal pattern with hypomethylation of differentiation-related genes in older HSPCs. A genome-wide promoter methylation analysis identified that promoter demethylation in hematopoietic-specific genes occurred during hematopoietic differentiation from human embryonic stem cells (hESCs) [13] and directional DNA methylation changes have been observed during the differention of HSPCs into different hematopoietic lineages in another genomic DNA methylation study [22].

Studies also found other DNA methylation markers in promoters of specific hematopoietic-related genes during HSPC development and differentiation. The HLA-G (human leukocyte antigen G) gene was hypomethylated in CD34+ cells compared to CD2+ lymphocytes [23]. Dynamic DNA methylation of the p15 gene promoter region was associated with proliferation, but not differentiation of normal human myeloid progenitors [24]. The gamma-globin gene promoter was highly methylated in the early stage of HSPCs and progressively demethylated during erythroid differentiation [25]. The DNA methylation of the MLL5 (mixed lineage leukemia-5) gene regulated HSC self-renewal [26]. The HIF1A (hypoxia-inducible factor 1 alpha) gene was hypermethylated and showed lower expression in HSPCs compared with other cell lines [27]. The X-linked HUMARA (human androgen receptor) gene showed methylation changes during the differentiation of hESCs into HSPCs, suggesting a methylation mechanism of the

${ }^{*}$ Corresponding author: Peng Xiao, Ph.D, Osteoporosis Research Center School of Medicine, Creighton University, 601 N. 30th St. Suite 6775, Omaha, NE 68131, USA, Tel.402-280-4283; Fax: 402-280-4284; E-mail: pxiao@creighton.edu

Received January 02, 2012; Accepted March 02, 2012; Published March 06 , 2012

Citation: Wang Y, Moore BT, Peng X, Xiao P (2012) Epigenetics and Hematopoietic Stem or Progenitor Cells. Human Genet Embryol S2:004. doi:10.4172/2161-0436. S2-004

Copyright: (ㅇ 2012 Wang Y, et al. This is an open-access article distributed under the terms of the Creative Commons Attribution License, which permits unrestricted use, distribution, and reproduction in any medium, provided the original author and source are credited. 
HUMARA gene in hESC-derived hematopoiesis [28]. The SALL4 (Sallike protein 4) gene regulated promoter methylation of silenced genes in primary HSPCs via recruitment of DNMTs [29].

\section{DNA methylation and aberrant HSPCs}

Myelodysplastic syndromes (MDS) are clonal HSC disorders with dysplasia in one or more hematopoietic cell lineages [30]. MDS displays ineffective hematopoiesis, impaired maturation of hematopoietic cells and an increased risk of developing acute leukemia [31]. DNA methylation plays an important role in the etiology of MDS. MDS patients mostly showed hypermethylation of the p15INK4B (CDKN2B, cyclin-dependent kinase 4 inhibitor B) gene promoter that may also be associated with disease progression [32]. The p15INK4B methylation in HSPCs in MDS patients was restricted to the MDS clone [33]. The CTNNA1 (catenin alpha-1) promoter was highly methylated and the gene was down-regulated in HSCs from MDS patients compared with normal HSCs, suggesting that DNA methylation of the CTNNA1 promoter in HSCs may contribute to human MDS development [34]. A biallelic hypermethylation pattern of the MGMT $\left(\mathbf{O}^{6}\right.$-methylguanineDNA methyltransferase) gene promoter was specifically shown in early myeloid precursor cells from therapy-related MDS patients [30]. Eighty percent (33/41) of MDS bone marrow samples showed hypermethylation of four tumor-associated genes, p15, p16, E-cadherin and MGMT [35]. A study found that hypermethylation silencing of the lineage-specific associated genes, survivin, CHK2 (checkpoint kinase 2) and WT1 (Wilms tumor 1), in MDS HSPCs, may contribute to an MDSspecific phenotype [36]. There were associations between the aberrant promoter methylation of the DNMT gene and its expression in highrisk MDS for all lineages and during erythropoiesis [37]. Moreover, DNMT3A mutation in HSPCs in MDS patients may alter DNA methylation of relevant genes implicated in the MDS pathogenesis [38]. Demethylation of the PI-PLCbeta1 (phosphoinositide-phospholipase $\mathrm{C}$ beta1) gene promoter correlated to the increased expression of transcription factors implicated in HSC differentiation, which hints the role of PI-PLCbeta1 in myeloid differentiation and as a potential therapy target for MDS [39].

Leukemia is a type of blood or bone marrow cancer caused by abnormal HSPC proliferation and differentiation. DNA methylation contributes to some of the subtypes of leukemia, such as AML (acute myelogenous leukemia), CMML (Chronic myelomonocytic leukemia), etc. CEBPA (CCAAT/enhancer-binding protein alpha) promoter CpGs were hypermethylated in AML cells compared with normal HSPCs $[40,41]$. A DNA methylation profiling study identified specific methylation signatures in HSPCs associated with AML and the methylation status of the $\mathrm{DBC} 1$ (deleted in bladder cancer protein 1) was validated as a predictor of AML with a normal karyotype [42]. A large AML patient cohort study revealed that IDH1/2 (isocitrate dehydrogenase 1/2)-mutant AMLs displayed global DNA hypermethylation and a specific hypermethylation signature, which also impaired hematopoietic differentiation and increased HSPC maker expression [43]. ABL1 (c-abl oncogene 1) promoter methylation has been discovered as an early marker in HSPCs for CML [44]. DNA methylation analysis in 127 JMML (juvenile myelomonocytic leukemia) cases identified frequent hypermethylated $\mathrm{CpG}$ islands in four genes, BMP4 (bone morphogenetic protein 4), CALCA (calcitonin-related polypeptide alpha), CDKN2B and RARB (retinoic acid receptor beta) [45].

The DNA methylation mechanism also affects other aberrant HSPC related diseases. For example, hypermethylation of the CXCR4 [chemokine ( $\mathrm{C}-\mathrm{X}-\mathrm{C}$ motif) receptor 4] promoter contributed to the development of abnormal HSPCs in primary myelofibrosis patients [46]. Hypomethylation of the p16 gene promoter and upregulated p16 expression were found in HSPCs from psoriasis compared with normal controls, suggesting that the promoter methylation status of the p16 gene in hematopoietic cells is involved in psoriasis [47].

\section{Histone modifications and HSPCs}

The histone tails on the nucleasome surface have many histone modifications, including acetylation, methylation, phosphorylation, poly-ADP ribosylation, ubiquitination and plycosylation [48]. Histone modifications determine the histone-DNA interaction and the interaction of nonhistone proteins with chromatin [49]. Gene expression can be regulated by histone modifications. Histone acetylation, catalyzed by histone acetyltransferases (HATs) such as MORF, MOZ, MOF, TIP60 and HBO, is one of the most studied modifications [50]. Histone acetylation mainly occurs at lysine residues of histone $\mathrm{H} 4$ and $\mathrm{H} 3$, which alters histone-DNA binding and binding codes of chromotin-interacting transcription factors [48]. The acetylation levels are determined by the balance between the action of HATs and histone deacetylaseas (HDACs) [51]. Histone methylation is another well-known histone modification, which regulates both transcriptional activation and repression [48]. Histone tails are normally methylated at lysine and arginine residues and the methylation levels are determined by the balance between histone methyltransferases (HMTs) and histone demethylases (HDMs) [48] One specific family of proteins, know as the Polycomb group (PcG), are known to play a critical role in epigenetic regulation in hematopoietic stem cells, mainly via histone modifications [52].

\section{Histone modifications and normal HSPC development and differentiation}

Recently, there are many studies on histone modifications for normal HSPC development and hematopoiesis. For histone acetylation, the transcription factor GABP (GA binding protein) activated transcription of HDACs including p300, which contributes to regulation of HSC self-renewal and differentiation [53]. Many Band T-lymphoid genes are associated with active $\mathrm{H} 3$ and $\mathrm{H} 4$ histone acetylation in human HSCs [54]. Histone $\mathrm{H} 3$ acetylation is important for activation of human beta-globin gene promoters during human and mouse HPC (hematopoietic progenitor cell) development [55]. A study demonstrated that BTG2 (B-cell translocation gene 2) enhanced retinoic acid-induced HSPC differentiation by modulating histone $\mathrm{H} 4$ methylation and acetylation of the RARbeta (retinoic acid receptor beta) gene [56]. Histone $\mathrm{H} 3$ acetylation in the mouse lambda5-VpreB1 locus may affect the B-cell development from mouse ESCs [57].

Many studies found histone acetylation markers and/or mechanisms in erythoid differentiation during hematopoiesis. Histone $\mathrm{H} 3$ and $\mathrm{H} 4$ acetylation peaks throughout the SCL (stem cell leukemia) gene in different hematopoietic cells were located at the SCL enhancer that targets the primitive erythroid lineage in vivo, which may provide a powerful tool for studying the biology of primitive erythroid lineage [58]. Increased histone acetylation in the gamma-globin gene correlated with increased gamma-globin expression in erythoid progenitor cells from adult baboons [59]. Continued expression of Myc (avian myelocytomatosis viral oncogene homolog) at physiological levels prevented mammalian erythoid cell maturation by blocking deacetylation of several lysine residues in histone $\mathrm{H} 3$ and $\mathrm{H} 4$ [60]. Deacetylation levels of histone H4 associated with the increased alpha 
(pi)-globin levels during the development in chick primary erythroid cells [61]. Recruitment of the SWI/SNF protein Brg1 (Brahma-related gene 1) repressed P4.2 (protein 4.2 ) expression by occupying the P4.2 gene promoter and reducing its histone $\mathrm{H} 3$ and $\mathrm{H} 4$ acetylation until the terminal differentiation of erythroid progenitors [62].

Based on the histone acetylation mechanisms in HSPC development and differentiation, HDAC and HAT inhibitors may be used for hemopoietic lineage differentiation or HSPC proliferation. VPA (valroic acid), an HDAC inhibitor, altered hematopoietic homeostasis in vitro by inhibition of erythroid differentiation and activation of the myelomonocytic pathway in HSPCs [63]. VPA increased CXCR4 expression by increasing the acetylation status of histone $\mathrm{H} 4$ in cord blood HSPCs, which may improve homing and engraftment of cord blood HSPC transplants [64]. VPA also enhanced cord blood HSPC self-renewal [65]. Normal CD34+ HSPCs showed inhibition of differentiation and an G2/M cell cycle arrest when treated with the HDAC inhibitor LAQ824, indicating the presence of a histone acetylation mechanism in HSPC development [66]. The HDAC inhibitor TSA (Trichostatin A) augmented histone acetylation in mouse HSPCs and resulted in an increase of cell frequency and survival [67]. Blocking of histone deacetylation by an HDAC inhibitor FK228 (depsipeptide) inhibited the differentiation of erythroid cells from human HSPCs [68]. Human HSPCs were able to be ex vivo expanded by a HAT inhibitor, Garcinol, by inhibition of HAT activity and histone acetylation [69].

For histone methylation, a study found that the forced expression of HDMT Fbxl10 (F-box and leucine-rich repeat protein 10) maintained HSC self-renewal, which for the first time highlighted a role of histone demethylation in the regulation of HSCs [70]. A unique HMT DOT1L (disruptor of telomere silencing 1-like) that specifically methylates histone $\mathrm{H} 3$ at lysine 79 acts as a critical regulator in mouse early hematopoiesis by regulating steady levels of GATA2 (an erythoid growth factor) and PU.1 ( a myelopoietic transcription factor) transcription and thus controlling the numbers of erythroid and myeloid cells in mice [71]. The HMT G9a displayed a dual role in the proper expression (repression and activation) of the beta-globin genes by a histone methylation mechanism to regulate differentiation of erythroid cells [72]. Genome-wide assessment of the concordance of histone histone $\mathrm{H} 3$ lysine 4 dimethylation (H3K4me2) and trimethylation (H3K4me3) in erythroid development by analyzing pluripotent, multipotent and unipotent cell types identified a subset of differentially methylated (H3K4me2+/me3-) genes highly enriched in lineage-specific hematopoietic genes, suggesting differential histone $\mathrm{H} 3 \mathrm{~K} 4$ methylation in lineage-specific differentiation [73]. Transcription factor Sox 2 has been demonstrated to assist in the formation of a monovalent histone methylation marker at an enhancer in the pro/pre-B cell-specific lambda5-VpreB1 locus in ESCs, indicating that there is a histone methylation regulatory mechanism via Sox 2 in B-cell development from ESCs [74]. The tumor suppressor menin directly activates Hoxa9 expression by binding to the Hoxa9 locus, facilitating methylation of $\mathrm{H} 3 \mathrm{~K} 4$ in the locus and recruiting the methylated $\mathrm{H} 3 \mathrm{~K} 4$ binding protein chd1 to the locus, which maintains normal hematopoiesis in mice [75].

\section{Histone modifications and aberrant HSPCs}

Histone modifications have also been found in diseased HSPCs and abnormal hematopoiesis. For histone methylation mechanisms, a study demonstrated that ectopic expression of the histone $\mathrm{H} 3$ lysine 36 dimethyl-specific HDM KDM2b/JHDM1b is sufficient to transform HSPCs and depletion of KDM2b/JHDM1b in HSPCs impaired leukemic transformation, indicating a critical role of $\mathrm{KDM} 2 \mathrm{~b} / \mathrm{JHDM} 1 \mathrm{~b}$ in leukemia development and maintenance [76]. The only known H3K79 HMT, Dot1, is pivotally required in MLL fusion protein-mediated leukemogenesis and is implicated as a potential therapeutic target [77]. Expression of AF4-MLL fusion protein in murine HSPCs caused altered histone methylation signatures and resulted in the development of proB ALL [78]. The MLL1 gene led to transformation of HSPCs into leukemia stem cell by binding to histone $\mathrm{H} 3 \mathrm{~K} 4 \mathrm{me} 3 / 2$ and recruiting factors that cause chromosomal translocations [79]. Increased histone H3K4 and H3K79 methylation with the SALL4 binding region of the BMI1 (B lymphoma Mo-MLV insertion region 1 homolog) promoter correlated with up-regulation of BMI1 in transgenic mice that over expressed human SALL4, which also transformed the mice from normal to MDS and AML stages [80].

\section{MiRNAs and HSPCs}

MiRNAs (18-24 nucleotide non-coding RNAs) are epigenetic regulatory components that mainly down-regulate gene expression by sequence-specific base paring at the 3'UTR (untranslated regions) of the target gene mRNA, resulting in mRNA degradation or inhibition of translation. They bind to target mRNA by the 'seed' sequence of the miRNA, nucleotides 2-8 (counted form the 5 'end) $[81,82]$. The miRNA regulatory mechanism has been implicated widely in cellular functions such as differentiation, proliferation, development and apoptosis [8184].

\section{MiRNAs and normal HSPC development and differentiation}

Normal HSPC development and differentiation are regulated by miRNAs. MiR-125b is an important miRNA in normal HSPCs. Overexpression of miR-125b enhanced hematopoietic engraftment in human immune system mice [85]. In a mouse study, miR-125b regulated HSC survival and promoted lymphoid-lineage differentiation [86]. Overexpression of miR-125b improved colony-formation in primary mouse HSPCs and promoted myelopoiesis in mouse bone marrow chimeras [87]. Moreover, miR-125b directly suppressed 20 novel targets in the p53 network in human, mouse and zebrafish stem cells and regulated cell proliferation and apoptosis [88].

MiR-126 is another critical HSPC miRNA. MiR-126 and HOXA9 protein were co expressed in HSCs and both were down regulated during progenitor cell differentiation [89]. Expression of miR-126 was found in HSCs and early progenitors, but not in differentiated progenitors in both mice and humans [90]. In G-CSF (granulocytecolonystimulating factor) mobilized CD34+ cells, miR-126 was upregulated [91]. MiRs-126/126* were up regulated and paralleled the expression of hematopoietic transcription factors RUNX1, SCL and PU.1 in CD34+ cells and overexpression of miRs-126/126* inhibited erythropoiesis from hESCs [92].

Two miRNAs, miR-144 and miR-451, play roles in erythropoiesis. MiR-144 specifically regulated the synthesis of embryonic alphahemoglobin during primitive erythropoiesis in zebrafish [93]. The miRNA miR-451 has been found to play a crucial role in promoting erythroid maturation by targeting the transcription factor GATA2 [94]. Further study found that both miR-144 and miR-451 induced erythropoiesis by targeting transcription factor GATA1 in zebrafish [95]. Recently, the role of the miR-144/451 cluster has also been found in mammalian erythropoiesis $[96,97]$.

There are other essential miRNAs in normal HSPCs and hematopoiesis. For example, miR-155 was upregulated in G-CSFmobilized CD34+ cells [91], inhibited both myeloid and erythroid 
differentiation from normal human HSPCs [98] and modulated megakaryopoiesis from human HSPCs by targeting ETS-1 and MEIS1 transcription factors [99]. The upregulation of miR-520h promoted differentiation of hHSCs into progenitor cells [100,101]. MiR-146a was strongly up regulated during megakaryopoiesis, but not erythropoiesis, in mice and humans [102] and overexpression of miR-146a in HSCs resulted in transient myeloid expansion, decreased erythropoiesis and impaired lymphopoiesis [103]. MiR-130a was expressed in HSPCs, but not differentiated progeny, in both mice and humans [90] and miR-130a targeted the transcription factor MAFB that is involved in platelet physiology [104]. MiR-24 stimulates myelopoiesis, blocks granulocytic differentiation and inhibits erythropoiesis [105,106]. MiR-181 preferentially induced B- or T-lymphopoiesis in mouse HSPCs $[107,108]$. Overexpression of miR-150 in HSCs impaired B cell development [109].

\section{MiRNAs and aberrant HSPCs}

The role of miRNAs in aberrant HSPCs and hematopoiesis has also been extensively studied. Aberrant expression of miR-155 and miR-150 is critical for the abnormal hematopoiesis. Expression levels of miR-155 were associated with subtypes of human AML [110] and miR-155 stimulated ALL (acute lymphoblastic leukemia) by downregulation of SHIP (Src homology 2 domain-containing inositol-5phosphatase) and C/EBPbeta (CCAAT enhancer-binding protein beta) in mice $[109,111]$. Sustained expression of miR-155 in mouse bone marrow cells injected with bacterial lipopolysaccharide (LPS) showed pathological myeloid proliferation, correlating with its overexpression in AML HSPCs [112]. Both miR-155 and miR-150 were aberrantly expressed in ATL (adult T-cell leukemia) cells [113]. Polycythemia vera (PV) is a myeloproliferative disorder from HSCs. Upregulation of miR-155 and miR-150 was identified in PV as compared to the normal erythroid progenitor cells [114].

Bellon et al. [113] found that miR-196b was specifically overexpressed in MLL HSCs. However, a later study also detected an up regulation of miR-196b in AML cells [110]. Furthermore, Schotte et al. [115] demonstrated that high expression of miR-196b is not limited to MLL, but also occurs in pediatric ALL cells with aberrant activation of the HOXA gene.

The levels of miR-221 and miR-222 were gradually and sharply down regulated in erythropoietic culture of cord blood HSPCs and transplantation experiments in mice revealed that miR-221 and 222 treatments of HSPCs damaged their engraftment capacity and stem cell activity [116]. Upregulation of miR-221 was correlated with AML [110]. Both miR-221 and 222 were progressively down regulated in normal erythropoiesis compared with the PV patient HSCs [114].

MiR-34a was highly overexpressed in 5q-deletion MDS patients, suggesting its role in increased apoptosis of bone marrow progenitors [117]. This miR-34a over expression was also observed in early MDS patients [118]. Over expression of miR-34a reprogrammed granulocytic differentiation of AML blast cells with CEBPA mutations, indicating miR-34a as a potential therapeutic target for AML with CEBPA mutations [119]. In addition, manipulated expression of miR-34a in K562 human leukemia cells inhibited cell proliferation, induced G1 arrest phase and promoted megakaryocyte differentiation, which suggested that miR-34a may be a potential treatment target for leukemia [120].
Studies also identified other essential miRNAs in aberrant HSPC development and hematopoiesis. MiR-146a was downregulated in 5q-MDS HSPCs in both mice [121] and humans [90]. Overexpression of miR-125b resulted in a dose-dependent myeloproliferative disorder and progressed to lethal myeloid leukemia in mice [85] and repression of miR-125b in Down syndrome acute megakaryoblastic leukemia cells impaired the cell proliferation and growth [122].

\section{Chromatin Remodeling and HSPCs}

Although the previous mechanisms of epigenetic regulation have been studied more extensively in hematopoietic stem/progenitor cells, chromatin remodeling is another epigenetic regulatory method that is used to influence gene expression in these cells. The remodeling of chromatin involves the modification of nucleosomes induced by various chromatin remodeling factors, thus providing another means of epigenetic regulation of gene expression [123]. Mi2-beta, an ATPase that is part of the nucleosome remodeling deacetylase (NuRD) complex, is critical for the differentiation of hematopoietic stem cells into immune cell lineages [124]. The phosphoprotein nucleolin, through its binding to the promoter region of the CD-34 gene in hematopoietic stem/progenitor cells, plays a significant role in gene expression. One of the mechanisms by which nucleolin may act to influence gene expression is via chromatin remodeling [125]. Enhancer of zeste homolog 2 (Ezh2), a PcG protein, was shown to help maintain the replicating potential of hematopoietic stem cells via stabilization of the chromatin structure [126].

\section{Conclusions and Perspectives}

In summary, we highlighted four major epigenetic regulatory mechanisms in the maintenance and differentiation of HSPCs, as well as the process of hematopoiesis. Many studies were focused on one specific mechanism in the HSPC system. However, in the real biological hematopoietic system, these four aspects should be dynamically interacted, particularly at the systematic level. Recent rapid development of high-throughput profiling technologies of epigenetic modifications on a genome-wide scale will definitely generate a more complete and multi-level epigenome for HSPCs and hematopoietic cells, which will systematically decipher the complicated epigenomic picture and provide promising therapeutic targets for various leukemias and other blood or immune related diseases.

\section{Acknowledgment}

The authors acknowledge grant support from the State of Nebraska (LB692) and NIH (R01AR04054496-02S1).

\section{References}

1. Berger SL, Kouzarides T, Shiekhattar R, Shilatifard A (2009) An operational definition of epigenetics. Genes Dev 23: 781-783.

2. Bird A (2007) Perceptions of epigenetics. Nature 447: 396-398.

3. Fazzari MJ, Greally JM (2010) Introduction to epigenomics and epigenomewide analysis. Methods Mol Biol 620: 243-265.

4. Cedar H, Bergman $Y$ (2011) Epigenetics of haematopoietic cell development Nat Rev Immunol 11: 478-488.

5. Zhu J, Park CW, Sjeklocha L, Kren BT, Steer CJ (2010) High-level genomic integration, epigenetic changes, and expression of sleeping beauty transgene. Biochemistry 49: 1507-1521.

6. Okano M, Xie S, Li E (1998) Cloning and characterization of a family of nove mammalian DNA (cytosine-5) methyltransferases. Nat Genet 19: 219-220.

7. Goto T, Monk M (1998) Regulation of X-chromosome inactivation in development in mice and humans. Microbiol Mol Biol Rev 62: 362-378. 
Citation: Wang Y, Moore BT, Peng X, Xiao P (2012) Epigenetics and Hematopoietic Stem or Progenitor Cells . Human Genet Embryol S2:004. doi:10.4172/2161-0436.S2-004

8. Schaefer CB, Ooi SK, Bestor TH, Bourc'his D (2007) Epigenetic decisions in mammalian germ cells. Science 316: 398-399.

9. Terranova R, Agherbi H, Boned A, Meresse S, Djabali M (2006) Histone and DNA methylation defects at Hox genes in mice expressing a SET domaintruncated form of MII. Proc Natl Acad Sci U S A 103: 6629-6634.

10. Trowbridge JJ, Snow JW, Kim J, Orkin SH (2009) DNA methyltransferase 1 is essential for and uniquely regulates hematopoietic stem and progenitor cells. Cell Stem Cell 5: 442-449.

11. Broske AM, Vockentanz L, Kharazi S, Huska MR, Mancini E, et al. (2009) DNA methylation protects hematopoietic stem cell multipotency from myeloerythroid restriction. Nat Genet 41: 1207-1215.

12. Tadokoro Y, Ema H, Okano M, Li E, Nakauchi H (2007) De novo DNA methyltransferase is essential for self-renewal, but not for differentiation, in hematopoietic stem cells. J Exp Med 204: 715-722.

13. Calvanese V, Fernandez AF, Urdinguio RG, Suarez-Alvarez B, Mangas C, et al. (2011) A promoter DNA demethylation landscape of human hematopoietic differentiation. Nucleic Acids Res 40: 116-131.

14. Bocker MT, Hellwig I, Breiling A, Eckstein V, Ho AD, et al. (2011) Genome-wide promoter DNA methylation dynamics of human hematopoietic progenitor cells during differentiation and aging. Blood 117: e182-e189.

15. Ji H, Ehrlich LI, Seita J, Murakami P, Doi A, et al. (2010) Comprehensive methylome map of lineage commitment from haematopoietic progenitors. Nature 467: 338-342.

16. Chung YS, Kim HJ, Kim TM, Hong SH, Kwon KR, et al. (2009) Undifferentiated hematopoietic cells are characterized by a genome-wide undermethylation dip around the transcription start site and a hierarchical epigenetic plasticity. Blood 114: 4968-4978.

17. Attema JL, Papathanasiou P, Forsberg EC, Xu J, Smale ST, et al. (2007) Epigenetic characterization of hematopoietic stem cell differentiation using miniChIP and bisulfite sequencing analysis. Proc Natl Acad Sci U S A 104: 12371-12376.

18. Civin Cl, Strauss LC, Brovall C, Fackler MJ, Schwartz JF, et al. (1984) Antigenic analysis of hematopoiesis. III. A hematopoietic progenitor cell surface antigen defined by a monoclonal antibody raised against KG-1a cells. J Immunol 133: 157-165.

19. Katz FE, Tindle R, Sutherland DR, Greaves MF (1985) Identification of a membrane glycoprotein associated with haemopoietic progenitor cells. Leuk Res 9: 191-198.

20. Andrews RG, Singer JW, Bernstein ID (1986) Monoclonal antibody 12-8 recognizes a 115-kd molecule present on both unipotent and multipotent hematopoietic colony-forming cells and their precursors. Blood 67: 842-845.

21. Watt SM, Karhi K, Gatter K, Furley AJ, Katz FE, et al. (1987) Distribution and epitope analysis of the cell membrane glycoprotein (HPCA-1) associated with human hemopoietic progenitor cells. Leukemia 1: 417-426.

22. Hodges E, Molaro A, Dos Santos CO, Thekkat P, Song Q, et al. (2011) Directional DNA methylation changes and complex intermediate states accompany lineage specificity in the adult hematopoietic compartment. Mol Cell 44: 17-28

23. Onno M, Amiot L, Bertho N, Drenou B, Fauchet R (1997) CpG methylation patterns in the 5' part of the nonclassical HLA-G gene in peripheral blood CD34+ cells and CD2+ lymphocytes. Tissue Antigens 49: 356-364.

24. Sakashita K, Koike K, Kinoshita T, Shiohara M, Kamijo T, et al. (2001) Dynamic DNA methylation change in the $\mathrm{CpG}$ island region of $\mathrm{p} 15$ during human myeloid development. J Clin Invest 108: 1195-1204.

25. Singh M, Lavelle D, Vaitkus K, Mahmud N, Hankewych M, et al. (2007) The gamma-globin gene promoter progressively demethylates as the hematopoietic stem progenitor cells differentiate along the erythroid lineage in baboon fetal liver and adult bone marrow. Exp Hematol 35: 48-55

26. Heuser M, Yap DB, Leung M, de Algara TR, Tafech A, et al. (2009) Loss of MLL5 results in pleiotropic hematopoietic defects, reduced neutrophil immune function, and extreme sensitivity to DNA demethylation. Blood 113: 1432-1443.

27. Walczak-Drzewiecka A, Ratajewski M, Pulaski L, Dastych J (2010) DNA methylation-dependent suppression of HIF1A in an immature hematopoietic cell line HMC-1. Biochem Biophys Res Commun 391: 1028-1032.

28. Mitjavila-Garcia MT, Bonnet ML, Yates F, Haddad R, Oudrhiri N, et al. (2010)
Partial reversal of the methylation pattern of the X-linked gene HUMARA during hematopoietic differentiation of human embryonic stem cells. J Mol Cell Biol 2: 291-298.

29. Yang J, Corsello TR, Ma Y (2011) Stem cell gene SALL4 suppresses transcription through recruitment of DNA methyltransferases. J Biol Chem 287 1996-2005.

30. Bogdanovic G, Jurisic V, Kraguljac N, Mrdjanovic J, Jakimov D, et al. (2007) Characteristics of novel myeloid precursor cell line, PC-MDS, established from a bone marrow of the patient with therapy-related myelodysplastic syndrome. Leuk Res 31: 1097-1105

31. Lasky J, Sakamoto KM (2005) Topics in pediatric leukemia--myelodysplastic and myeloproliferative disorders of childhood. Med Gen Med 7: 21.

32. Uchida T, Kinoshita T, Nagai H, Nakahara Y, Saito H, et al. (1997) Hypermethylation of the p15INK4B gene in myelodysplastic syndromes. Blood 90: 1403-1409.

33. Aoki E, Uchida T, Ohashi $\mathrm{H}$, Nagai H, Murase T, et al. (2000) Methylation status of the p15INK4B gene in hematopoietic progenitors and peripheral blood cells in myelodysplastic syndromes. Leukemia 14: 586-593.

34. Liu TX, Becker MW, Jelinek J, Wu WS, Deng M, et al. (2007) Chromosome $5 \mathrm{q}$ deletion and epigenetic suppression of the gene encoding alpha-catenin (CTNNA1) in myeloid cell transformation. Nat Med 13: 78-83.

35. Solomon PR, Munirajan AK, Tsuchida N, Muthukumarasamy K, Rathinavel A, et al. (2008) Promoter hypermethylation analysis in myelodysplastic syndromes: diagnostic \& prognostic implication. Indian J Med Res 127: 52-57.

36. Hopfer O, Komor M, Koehler IS, Schulze M, Hoelzer D, et al. (2007) DNA methylation profiling of myelodysplastic syndrome hematopoietic progenito cells during in vitro lineage-specific differentiation. Exp Hematol 35: 712-723.

37. Hopfer O, Komor M, Koehler IS, Freitag C, Schulze M, et al. (2009) Aberran promotor methylation in MDS hematopoietic cells during in vitro lineage specific differentiation is differently associated with DNMT isoforms. Leuk Res 33: 434 442

38. Walter MJ, Ding L, Shen D, Shao J, Grillot M, et al. (2011) Recurrent DNMT3A mutations in patients with myelodysplastic syndromes. Leukemia 25: 1153 1158.

39. Follo MY, Russo D, Finelli C, Mongiorgi S, Clissa C, et al. (2011) Epigenetic regulation of nuclear $\mathrm{PI}-\mathrm{PLCb}$ ta1 signaling pathway in low-risk MDS patients during azacitidine treatment. Leukemia

40. Negrotto S, Ng KP, Jankowska AM, Bodo J, Gopalan B, et al. (2011) CpG methylation patterns and decitabine treatment response in acute myeloid leukemia cells and normal hematopoietic precursors. Leukemia 26: 244-254.

41. Figueroa ME, Wouters BJ, Skrabanek L, Glass J, Li Y, et al. (2009) Genomewide epigenetic analysis delineates a biologically distinct immature acute leukemia with myeloid/T-lymphoid features. Blood 113: 2795-2804.

42. Alvarez S, Suela J, Valencia A, Fernandez A, Wunderlich M, et al. (2010) DNA methylation profiles and their relationship with cytogenetic status in adult acute myeloid leukemia. PLoS One 5: e12197.

43. Figueroa ME, Abdel-Wahab O, Lu C, Ward PS, Patel J, et al. (2010) Leukemic IDH1 and IDH2 mutations result in a hypermethylation phenotype, disrupt TET2 function, and impair hematopoietic differentiation. Cancer Cell 18: 553-567.

44. Sun B, Jiang G, Zaydan MA, La Russa VF, Safah H, et al. (2001) ABL1 promoter methylation can exist independently of BCR-ABL transcription in chronic myeloid leukemia hematopoietic progenitors. Cancer Res 61: 69316937.

45. Olk-Batz C, Poetsch AR, Nollke P, Claus R, Zucknick M, et al. (2011) Aberran DNA methylation characterizes juvenile myelomonocytic leukemia with poor outcome. Blood 117: 4871-4880.

46. Bogani C, Ponziani V, Guglielmelli P, Desterke C, Rosti V, et al. (2008) Hypermethylation of CXCR4 promoter in CD34+ cells from patients with primary myelofibrosis. Stem Cells 26: 1920-1930.

47. Zhang K, Zhang R, Li X, Yin G, Niu X, et al. (2007) The mRNA expression and promoter methylation status of the p16 gene in colony-forming cells with high proliferative potential in patients with psoriasis. Clin Exp Dermatol 32: 702-708.

48. Kouzarides T (2007) Chromatin modifications and their function. Cell 128: 693 705. 
Citation: Wang Y, Moore BT, Peng X, Xiao P (2012) Epigenetics and Hematopoietic Stem or Progenitor Cells . Human Genet Embryol S2:004. doi:10.4172/2161-0436.S2-004

49. Turner BM (2002) Cellular memory and the histone code. Cell 111: 285-291.

50. Esteller M (2007) Cancer epigenomics: DNA methylomes and histonemodification maps. Nat Rev Genet 8: 286-298.

51. Villar-Garea A, Esteller M (2004) Histone deacetylase inhibitors: understanding a new wave of anticancer agents. Int J Cancer 112: 171-178.

52. Konuma T, Oguro H, Iwama A (2010) Role of the polycomb group proteins in hematopoietic stem cells. Dev Growth Differ 52: 505-516.

53. Yu S, Cui K, Jothi R, Zhao DM, Jing X, et al. (2011) GABP controls a critical transcription regulatory module that is essential for maintenance and differentiation of hematopoietic stem/progenitor cells. Blood 117: 2166-2178.

54. Maes J, Maleszewska M, Guillemin C, Pflumio F, Six E, et al. (2008) Lymphoidaffiliated genes are associated with active histone modifications in human hematopoietic stem cells. Blood 112: 2722-2729.

55. Bottardi S, Aumont A, Grosveld F, Milot E (2003) Developmental stage-specific epigenetic control of human beta-globin gene expression is potentiated in hematopoietic progenitor cells prior to their transcriptional activation. Blood 102: 3989-3997.

56. Passeri D, Marcucci A, Rizzo G, Billi M, Panigada M, et al. (2006) Btg2 enhances retinoic acid-induced differentiation by modulating histone $\mathrm{H} 4$ methylation and acetylation. Mol Cell Biol 26: 5023-5032.

57. Szutorisz H, Canzonetta C, Georgiou A, Chow CM, Tora L, et al. (2005) Formation of an active tissue-specific chromatin domain initiated by epigenetic marking at the embryonic stem cell stage. Mol Cell Biol 25: 1804-1820.

58. Delabesse E, Ogilvy S, Chapman MA, Piltz SG, Gottgens B, et al. (2005) Transcriptional regulation of the SCL locus: identification of an enhancer that targets the primitive erythroid lineage in vivo. Mol Cell Biol 25: 5215-5225.

59. Chin J, Singh M, Banzon V, Vaitkus K, lbanez V, et al. (2009) Transcriptiona activation of the gamma-globin gene in baboons treated with decitabine and in cultured erythroid progenitor cells involves different mechanisms. Exp Hematol 37: 1131-1142

60. Jayapal SR, Lee KL, Ji P, Kaldis P, Lim B, et al. (2010) Down-regulation of Myc is essential for terminal erythroid maturation. J Biol Chem 285: 40252-40265.

61. Singal R, vanWert JM, Ferdinand L Jr (2002) Methylation of alpha-type embryonic globin gene alpha pi represses transcription in primary erythroid cells. Blood 100: 4217-4222.

62. Xu Z, Meng X, Cai Y, Koury MJ, Brandt SJ (2006) Recruitment of the SWI/ SNF protein Brg1 by a multiprotein complex effects transcriptional repression in murine erythroid progenitors. Biochem J 399: 297-304.

63. Chateauvieux S, Eifes S, Morceau F, Grigorakaki C, Schnekenburger M, et al. (2011) Valproic acid perturbs hematopoietic homeostasis by inhibition of erythroid differentiation and activation of the myelo-monocytic pathway. Biochem Pharmacol 81: 498-509.

64. Gul H, Marquez-Curtis LA, Jahroudi N, Lo J, Turner AR, et al. (2009) Valproic acid increases CXCR4 expression in hematopoietic stem/progenitor cells by chromatin remodeling. Stem Cells Dev 18: 831-838.

65. Burba I, Colombo GI, Staszewsky LI, De SM, Devanna P, et al. (2011) Histone deacetylase inhibition enhances self renewal and cardioprotection by human cord blood-derived CD34 cells. PLoS One 6: e22158.

66. Schwarz K, Romanski A, Puccetti E, Wietbrauk S, Vogel A, et al. (2011) The deacetylase inhibitor LAQ824 induces notch signalling in haematopoietic progenitor cells. Leuk Res 35: 119-125.

67. Obier N, Uhlemann CF, Muller AM (2010) Inhibition of histone deacetylases by Trichostatin A leads to a HoxB4-independent increase of hematopoietic progenitor/stem cell frequencies as a result of selective survival. Cytotherapy 12: 899-908.

68. Fujieda A, Katayama N, Ohishi K, Yamamura K, Shibasaki T, et al. (2005) A putative role for histone deacetylase in the differentiation of human erythroid cells. Int J Oncol 27: 743-748.

69. Nishino T, Wang C, Mochizuki-Kashio M, Osawa M, Nakauchi H, et al. (2011) Ex vivo expansion of human hematopoietic stem cells by garcinol, a potent inhibitor of histone acetyltransferase. PLoS One 6: e24298.

70. Konuma T, Nakamura S, Miyagi S, Negishi M, Chiba T, et al. (2011) Forced expression of the histone demethylase $\mathrm{Fbxl} 10$ maintains self-renewing hematopoietic stem cells. Exp Hematol 39: 697-709.
71. Feng Y, Yang Y, Ortega MM, Copeland JN, Zhang M, et al. (2010) Early mammalian erythropoiesis requires the Dot $1 \mathrm{~L}$ methyltransferase. Blood 116 4483-4491.

72. Chaturvedi CP, Hosey AM, Palii C, Perez-Iratxeta C, Nakatani Y, et al. (2009) Dual role for the methyltransferase G9a in the maintenance of beta-globin gene transcription in adult erythroid cells. Proc Natl Acad Sci U S A 106: 1830318308.

73. Orford K, Kharchenko P, Lai W, Dao MC, Worhunsky DJ, et al. (2008) Differential H3K4 methylation identifies developmentally poised hematopoietic genes. Dev Cell 14: 798-809.

74. Liber D, Domaschenz R, Holmqvist PH, Mazzarella L, Georgiou A, et al. (2010) Epigenetic priming of a pre-B cell-specific enhancer through binding of Sox2 and Foxd3 at the ESC stage. Cell Stem Cell 7: 114-126.

75. Chen YX, Yan J, Keeshan K, Tubbs AT, Wang H, et al. (2006) The tumor suppressor menin regulates hematopoiesis and myeloid transformation by influencing Hox gene expression. Proc Natl Acad Sci U S A 103: 1018-1023.

76. He J, Nguyen AT, Zhang Y (2011) KDM2b/JHDM1b, an H3K36me2-specific demethylase, is required for initiation and maintenance of acute myeloid leukemia. Blood 117: 3869-3880.

77. Chang MJ, Wu H, Achille NJ, Reisenauer MR, Chou CW, et al. (2010) Histone H3 lysine 79 methyltransferase Dot1 is required for immortalization by MLL oncogenes. Cancer Res 70: 10234-10242.

78. Benedikt A, Baltruschat S, Scholz B, Bursen A, Arrey TN, et al. (2011) The leukemogenic AF4-MLL fusion protein causes P-TEFb kinase activation and altered epigenetic signatures. Leukemia 25: 135-144.

79. Wang Z, Song J, Milne TA, Wang GG, Li H, et al. (2010) Pro isomerization in MLL1 PHD3-bromo cassette connects H3K4me readout to CyP33 and HDACmediated repression. Cell 141: 1183-1194

80. Yang J, Chai L, Liu F, Fink LM, Lin P, et al. (2007) Bmi-1 is a target gene for SALL4 in hematopoietic and leukemic cells. Proc Natl Acad Sci U S A 104 10494-10499.

81. Lewis BP, Burge CB, Bartel DP (2005) Conserved seed pairing, often flanked by adenosines, indicates that thousands of human genes are microRNA targets. Cell 120: 15-20.

82. Lewis BP, Shih IH, Jones-Rhoades MW, Bartel DP, Burge CB (2003) Prediction of mammalian microRNA targets. Cell 115: 787-798

83. Bartel DP (2004) MicroRNAs: genomics, biogenesis, mechanism, and function Cell 116: 281-297.

84. Harfe BD (2005) MicroRNAs in vertebrate development. Curr Opin Genet Dev 15: $410-415$

85. O'Connell RM, Chaudhuri AA, Rao DS, Gibson WS, Balazs AB, et al. (2010) MicroRNAs enriched in hematopoietic stem cells differentially regulate longterm hematopoietic output. Proc Natl Acad Sci U S A 107: 14235-14240.

86. Ooi AG, Sahoo D, Adorno M, Wang Y, Weissman IL, et al. (2010) MicroRNA$125 \mathrm{~b}$ expands hematopoietic stem cells and enriches for the lymphoid-balanced and lymphoid-biased subsets. Proc Natl Acad Sci U S A 107: 21505-21510.

87. Surdziel E, Cabanski M, Dallmann I, Lyszkiewicz M, Krueger A, et al. (2011) Enforced expression of miR-125b affects myelopoiesis by targeting multiple signaling pathways. Blood 117: 4338-4348.

88. Le MT, Shyh-Chang N, Khaw SL, Chin L, Teh C, et al. (2011) Conserved regulation of $\mathrm{p} 53$ network dosage by microRNA-125b occurs through evolving miRNA-target gene pairs. PLoS Genet 7: e1002242.

89. Shen WF, Hu YL, Uttarwar L, Passegue E, Largman C (2008) MicroRNA-126 regulates HOXA9 by binding to the homeobox. Mol Cell Biol 28: 4609-4619.

90. Gentner B, Visigalli I, Hiramatsu H, Lechman E, Ungari S, et al. (2010) Identification of hematopoietic stem cell-specific miRNAs enables gene therapy of globoid cell leukodystrophy. Sci Transl Med 2: 58ra84.

91. Donahue RE, Jin P, Bonifacino AC, Metzger ME, Ren J, et al. (2009) Plerixafo (AMD3100) and granulocyte colony-stimulating factor (G-CSF) mobilize different CD34+ cell populations based on global gene and microRNA expression signatures. Blood 114: 2530-2541.

92. Huang X, Gschweng E, Van HB, Cheng D, Mikkola HK, et al. (2011) Regulated expression of microRNAs-126/126* inhibits erythropoiesis from human embryonic stem cells. Blood 117: 2157-2165. 
Citation: Wang Y, Moore BT, Peng X, Xiao P (2012) Epigenetics and Hematopoietic Stem or Progenitor Cells . Human Genet Embryol S2:004. doi:10.4172/2161-0436.S2-004

93. Fu YF, Du TT, Dong M, Zhu KY, Jing CB, et al. (2009) Mir-144 selectively regulates embryonic alpha-hemoglobin synthesis during primitive erythropoiesis. Blood 113: 1340-1349.

94. Pase L, Layton JE, Kloosterman WP, Carradice D, Waterhouse PM, et al (2009) miR-451 regulates zebrafish erythroid maturation in vivo via its target gata2. Blood 113: 1794-1804

95. Dore LC, Amigo JD, Dos Santos CO, Zhang Z, Gai X, et al. (2008) A GATA-1regulated microRNA locus essential for erythropoiesis. Proc Natl Acad Sci U S A 105: 3333-3338.

96. Rasmussen KD, Simmini S, Abreu-Goodger C, Bartonicek N, Di GM, et al. (2010) The miR-144/451 locus is required for erythroid homeostasis. J Exp Med 207: 1351-1358

97. Papapetrou EP, Korkola JE, Sadelain M (2010) A genetic strategy for single and combinatorial analysis of miRNA function in mammalian hematopoietic stem cells. Stem Cells 28: 287-296.

98. Georgantas RW 3rd, Hildreth R, Morisot S, Alder J, Liu CG, et al. (2007) CD34+ hematopoietic stem-progenitor cell microRNA expression and function: a circuit diagram of differentiation control. Proc Natl Acad Sci U S A 104: 2750-2755.

99. Romania P, Lulli V, Pelosi E, Biffoni M, Peschle C, et al. (2008) MicroRNA 155 modulates megakaryopoiesis at progenitor and precursor level by targeting Ets-1 and Meis1 transcription factors. Br J Haematol 143: 570-580.

100. Merkerova M, Vasikova A, Belickova M, Bruchova H (2010) MicroRNA expression profiles in umbilical cord blood cell lineages. Stem Cells Dev 19: $17-26$.

101. Liao R, Sun J, Zhang L, Lou G, Chen M, et al. (2008) MicroRNAs play a role in the development of human hematopoietic stem cells. J Cell Biochem 104: 805-817.

102. Opalinska JB, Bersenev A, Zhang Z, Schmaier AA, Choi J, et al. (2010) MicroRNA expression in maturing murine megakaryocytes. Blood 116: e128-e138.

103. Starczynowski DT, Kuchenbauer F, Wegrzyn J, Rouhi A, Petriv O, et al (2011) MicroRNA-146a disrupts hematopoietic differentiation and survival. Exp Hematol 39: 167-178.

104.Garzon R, Pichiorri F, Palumbo T, luliano R, Cimmino A, et al. (2006) MicroRNA fingerprints during human megakaryocytopoiesis. Proc Natl Acad Sci U S A 103: 5078-5083.

105.Zaidi SK, Dowdy CR, van Wijnen AJ, Lian JB, Raza A, et al. (2009) Altered Runx1 subnuclear targeting enhances myeloid cell proliferation and blocks differentiation by activating a miR-24/MKP-7/MAPK network. Cancer Res 69 : 8249-8255.

106. Wang Q, Huang Z, Xue H, Jin C, Ju XL, et al. (2008) MicroRNA miR-24 inhibits erythropoiesis by targeting activin type I receptor ALK4. Blood 111: 588-595.

107.Papapetrou EP, Kovalovsky D, Beloeil L, Sant'angelo D, Sadelain M (2009) Harnessing endogenous miR-181a to segregate transgenic antigen receptor expression in developing versus post-thymic $\mathrm{T}$ cells in murine hematopoietic chimeras. J Clin Invest 119: 157-168.

108. Chen CZ, Li L, Lodish HF, Bartel DP (2004) MicroRNAs modulate hematopoietic lineage differentiation. Science 303: 83-86.

109. Zhou B, Wang S, Mayr C, Bartel DP, Lodish HF (2007) miR-150, a microRNA expressed in mature $B$ and $T$ cells, blocks early $B$ cell development when expressed prematurely. Proc Natl Acad Sci U S A 104: 7080-7085

110. Cammarata G, Augugliaro L, Salemi D, Agueli C, La RM, et al. (2010) Differential expression of specific microRNA and their targets in acute myeloid leukemia. Am J Hematol 85: 331-339.

111. Costinean S, Sandhu SK, Pedersen IM, Tili E, Trotta R, et al. (2009) Src homology 2 domain-containing inositol-5-phosphatase and CCAAT enhancerbinding protein beta are targeted by miR-155 in B cells of Emicro-MiR-155 transgenic mice. Blood 114: 1374-1382.
112. O'Connell RM, Rao DS, Chaudhuri AA, Boldin MP, Taganov KD, et al. (2008) Sustained expression of microRNA-155 in hematopoietic stem cells causes a myeloproliferative disorder. J Exp Med 205: 585-594.

113. Bellon M, Lepelletier Y, Hermine O, Nicot C (2009) Deregulation of microRNA involved in hematopoiesis and the immune response in HTLV-I adult T-cell leukemia. Blood 113: 4914-4917

114. Bruchova H, Yoon D, Agarwal AM, Mendell J, Prchal JT (2007) Regulated expression of microRNAs in normal and polycythemia vera erythropoiesis. Exp Hematol 35: 1657-1667

115. Schotte D, Lange-Turenhout EA, Stumpel DJ, Stam RW, Buijs-Gladdines JG, et al. (2010) Expression of miR-196b is not exclusively MLL-driven but is especially linked to activation of HOXA genes in pediatric acute lymphoblastic leukemia. Haematologica 95: 1675-1682.

116. Felli N, Fontana L, Pelosi E, Botta R, Bonci D, et al. (2005) MicroRNAs 221 and 222 inhibit normal erythropoiesis and erythroleukemic cell growth via kit receptor down-modulation. Proc Natl Acad Sci U S A 102: 18081-18086.

117. Votavova H, Grmanova M, Dostalova MM, Belickova M, Vasikova A, et al (2011) Differential expression of microRNAs in CD34+ cells of $5 q$ - syndrome. J Hematol Oncol 4: 1

118. Dostalova MM, Krejcik Z, Votavova H, Belickova M, Vasikova A, et al. (2011) Distinctive microRNA expression profiles in CD34+ bone marrow cells from patients with myelodysplastic syndrome. Eur J Hum Genet 19: 313-319.

119. Pulikkan JA, Peramangalam PS, Dengler V, Ho PA, Preudhomme C et al. (2010) C/EBPalpha regulated microRNA-34a targets E2F3 during granulopoiesis and is down-regulated in AML with CEBPA mutations. Blood 116: 5638-5649.

120. Navarro F, Gutman D, Meire E, Caceres M, Rigoutsos I, et al. (2009) miR-34a contributes to megakaryocytic differentiation of K562 cells independently of p53. Blood 114: 2181-2192.

121. Starczynowski DT, Kuchenbauer F, Argiropoulos B, Sung S, Morin R, et al. (2010) Identification of miR-145 and miR-146a as mediators of the $5 q$ syndrome phenotype. Nat Med 16: 49-58

122. Klusmann JH, Li Z, Bohmer K, Maroz A, Koch ML, et al. (2010) miR-125b-2 is a potential oncomiR on human chromosome 21 in megakaryoblastic leukemia. Genes Dev 24: 478-490.

123.Zhou Y, Kim J, Yuan X, Braun T (2011) Epigenetic modifications of stem cells: a paradigm for the control of cardiac progenitor cells. Circ Res 109: 1067 1081

124. Yoshida T, Hazan I, Zhang J, Ng SY, Naito T, et al. (2008) The role of the chromatin remodeler Mi-2beta in hematopoietic stem cell self-renewal and multilineage differentiation. Genes Dev 22: 1174-1189.

125. Grinstein E, Du Y, Santourlidis S, Christ J, Uhrberg M, et al. (2007) Nucleolin regulates gene expression in CD34-positive hematopoietic cells. J Biol Chem 282: 12439-12449.

126. Kamminga LM, Bystrykh LV, de BA, Houwer S, Douma J, et al. (2006) The Polycomb group gene Ezh2 prevents hematopoietic stem cell exhaustion. Blood 107: 2170-2179.

This article was originally published in a special issue, Epigenetics, stem cells and tumorigenicity handled by Editor(s). Dr. Yue Zhang, Harvard Medical School, USA; Yujing Li, Emory University School of Medicine, USA, Yanhong Ji, Xian Jiaotong University, China 